\title{
O MONGE DO NARIZ LONGO ${ }^{1}$
}

Luiza Nana Yoshida

RESUMO: O presente artigo pretende analisar o significado literário da narrativa setsuwa, enfatizando algumas das suas principais características que a estabelecem como um gênero complementar das narrativas monogatari da época Heian.

ABSTRACT: This paper intends to analyse the literary meaning of setsuwa narrative, emphasizing its main characteristics which stablish it as a complementary genre of Heian monogatari narrative.

PALAVRAS-CHAVE: narrativas setsuwa, Konjaku Monogatari, cômico, grotesco. KEYWORDS: setsuwa narrative, Konjaku Monogatari, comic, grotesque.

O período clássico da Literatura Japonesa que se estende do século VIII até meados do século XIX, legou-nos inúmeras obras de incontestável valor literário que, embora timidamente, vêm sendo reconhecidas a nível mundial.

No Japão, não diferindo de outros países, a literatura escrita, inicialmente, constituía privilégio de poucos, e a sua popularização só vai ocorrer a partir do século XVII, com o desenvolvimento da impressão de livros, através da utilização da técnica da xilogravura.

As primeiras obras clássicas (do século VIII) encontram-se escritas em chinês ou com a utilização do ideograma chinês, visto que o Japão não possuía ainda uma

1. Parte da Tese de Doutorado, apresentada à Faculdade de Filosofia, Letras e Ciências Humanas da USP. 
escrita própria. Somente a partir do século X, com o desenvolvimento de uma grafia própria, o Japão passa a produzir obras escritas inteiramente em japonês. Devido a coincidências de vários fatores históricos, políticos e culturais, assiste-se, nos séculos $\mathrm{X}$ e XI, à produção de inúmeras obras, dos mais variados gêneros (narrativa ficcional, diário literário, textos ensaísticos, entre outros), escritas pelas damas da Corte, mulheres altamente instruídas que chegaram a constituir uma camada intelectual, sustentadora de grande parte da produção literária da época. Não é sem razão, portanto, que existe quase uma unanimidade em se considerar a obra Genji Monogatari (Narrativas de Genji), escrita, no século XI, pela dama da Corte Murasaki Shikibu, como a obraprima da Literatura Clássica. Trata-se de uma obra que retrata essencialmente a existência de Hikaru Genji, nascido príncipe imperial, mas que, por contingências do destino, é afastado da linha sucessória, tornando-se súdito da família em que nascera. Através da relação, direta ou indireta, de Genji com as demais personagens, a autora cria uma complicada trama que conta a vida de Genji, desde o seu nascimento até a sua morte, assim como parte da existência do seu filho Kaoru. Norteada pela convicção de que a ficção retrataria mais fielmente a realidade, do que a própria crônica histórica, Murasaki Shikibu foi capaz de descrever não só a vida de um nobre da época Heian, mas a existência de uma personagem que reflete as características universais do próprio ser humano. Possuindo um domínio excepcional da língua materna e certamente o conhecimento de alguns clássicos chineses, praticamente vetados às mulheres, na época, a autora conseguiu, através de Genji Monogatari, perpetuar o refinado estilo de vida dos nobres de Heian.

Assim, as narrativas clássicas (monogatari), como Genji Monogatari, caracterizam-se pelo refinado lirismo e refletem a apurada sensibilidade adotada como um ideal estético pela nobreza de Heian.

Se, dessa forma, as narrativas clássicas visam enfatizar as características consideradas altas, como a beleza, a elegância, a sutileza, a sensibilidade, as narrativas conhecidas como setsuwa colocam principalmente em evidência as características consideradas baixas: a repugnância, a vulgaridade, a hipérbole, a comicidade, a transgressão etc. As características contrastantes vão mais além: quanto à sua extensão, as narrativas monogatari são, em geral, longas, o ambiente encontra-se praticamente centrado no mundo da nobreza, assim como as suas personagens. As narrativas setsuwa, por sua vez, são breves, seus espaços sociais e suas personagens são infinitamente variadas. Nesse sentido, o caráter de complementaridade entre os dois tipos de narrativa torna-se evidente. Pode-se dizer, ainda, que as narrativas monogatari tornaram-se populares, principalmente entre as mulheres da aristocracia Heian, que encontraram na leitura uma rara possibilidade de ampliar um pouco mais a sua visão de mundo, ainda que de forma imaginária, visto que passavam a sua existência nos limites dos lares ou no interior do palácio imperial. Numa época em que os livros eram manuscritos, sabese que a difusão destes ocorre através de empréstimo ou da prática da cópia, sendo conhecidos casos em que manuscritos luxuosamente encadernados de narrativas fazerem, por vezes, parte do enxoval das jovens nubentes.

No que concerne às narrativas setsuwa, a primeira coletânea data do século IX. Denominada Nihon Ryôiki (Relatos Milagrosos do Japão), foi compilada pelo monge 
Keikai (ou Kyôkai), e reúne pouco mais de cem narrativas de cunho budista, escritas em estilo chinês.

A obra Konjaku Monogatarishû (Coletânea de Narrativas que o Agora É o Passado), compilada no século XII e de autoria desconhecida, é considerada a primeira coletânea a reunir narrativas de cunho budista, assim como as de cunho secular. Tratase de uma obra monumental, composta por mais de mil narrativas originárias da Índia, da China e do Japão, classificadas conforme temas. Escrita com a utilização do ideograma chinês e do fonograma japonês denominado katakana, pode-se dizer que o seu estilo é uma forma peculiar do estilo misto sino-japonês (wakan konkôbun) que alcança a sua perfeição, no século XIII.

Embora coletâneas de narrativas setsuwa tenham sido escritas, posteriormente, também em estilo japonês (wabun) - estilo que, no início, foi utilizado predominantemente pelas mulheres - há de se destacar que as narrativas setsuwa foram escritas, originariamente, em "estilo masculino" (em chinês ou em estilo misto sino-japonês). Tal aspecto configura-se também como uma característica contrastante, na medida em que, por um determinado tempo, houve uma separação de gêneros, no próprio estilo de escrita: as mulheres escreviam em estilo japonês com o uso do fonograma japonês hiragana, enquanto os homens escreviam em estilo chinês ou sino-japonês, com o uso do ideograma chinês e/ou do fonograma japonês katakana.

Dessa forma, o próprio estilo utilizado nas coletâneas de narrativas setsuwa era inacessível às mulheres, assim como o mundo (ou os mundos) ali retratado em nada se identificava com aquele (único) que elas conheciam. Também nesse aspecto, as narrativas setsuwa parecem apresentar o caráter da complementaridade em relação às narrativas monogatari.

Cabe colocar que este artigo não visa a realização de um estudo comparativo ou contrastivo entre os dois tipos de narrativas acima aludidas. Nem tem a pretensão de apresentar um estudo conclusivo sobre a obra Konjaku Monogatarishû ou o gênero setsuwa, através da análise de apenas uma de suas narrativas. Tem, sim, o intuito de apresentar um aspecto literário significativo das narrativas setsuwa que, isoladas, podem tomar a forma de simples anedotas, estórias antigas, casos etc., mas reunidas em uma coletânea, passam a fazer parte de um todo, que é o universo do setsuwa. Este universo, por sua vez, vem complementar o mundo da aristocracia Heian, retratado nas narrativas monogatari.

Tratando-se da descrição de um mundo "desconhecido" (outros países, outras localidades, vidas pessoais, classe social diversa), as narrativas setsuwa são registradas sob a forma de tradição oral (histórias que se contam pelo mundo), enquanto as narrativas monogatari são estabelecidas como ficção, que, segundo a concepção de Murasaki Shikibu, seriam o retrato mais fiel da realidade, conforme aludido anteriormente.

A narrativa de Konjaku Monogatarishû escolhida para a realização do presente trabalho intitula-se Sobre o Nariz do Monge Palaciano Zenchi de Ikenoo. Trata-se da narrativa 20 do tomo XXVIII (que reúne 44 narrativas cômicas do Japão). Sendo de pequena extensão, colocaremos, a seguir, a sua tradução integral. 


\section{XXVIII/20 - Sobre o nariz do monge palaciano Zenchi de Ikenoo.}

(1) O agora é passado, morava no local denominado Ikenoo $^{2}$, um monge palaciano ${ }^{3}$ chamado Zenchi ${ }^{4}$. Possuía uma forte convicção religiosa, era versado nos ensinamentos esotéricos do Budismo e empenhava-se na prática de suas leis, razão pela qual não havia qualquer sinal de decadência, fosse nas edificações do templo de Ikenoo, fosse nos alojamentos dos monges; a luz votiva ou as oferendas a Buda eram permanentes, e nunca faltavam, para o monge, as oferendas em produtos ou dinheiro, sendo ainda freqüentes a realização de preleções, estando, portanto, o templo sempre repleto de monges que lotavam os alojamentos. Na sala de banho, não havia um dia em que os monges do templo não esquentassem a água, e a agitada movimentação dos monges banhistas afigurava-se extremamente animada. Sendo um templo de tal prosperidade, nas suas cercanias, pequenas casas foram se erguendo, formando um animado povoado.

(2) A propósito, o nariz deste monge palaciano era longo, cerca de 15 a $18 \mathrm{~cm}^{5}$, razão pela qual era visto pendente abaixo do queixo. A cor era de um vermelho-arroxeado e, tal qual uma casca de laranja, pontilhado por pústulas que o tornavam intumescido. Isso coçava terrivelmente, sem parar. Então, ele fervia, num bule, a água à alta temperatura, abria, numa bandeja de madeira, um orifício que permitisse a passagem do nariz, e para que o rosto não fosse chamuscado pelas chamas, passava o nariz por esse orifício, enfiava-o no bule e o escaldava, até que ficasse arroxeado. Deitava-se, então, de lado, calçava o nariz e fazia com que o pisassem. Bem escaldado, o nariz ficava enegrecido, e de cada uma das pústulas saía algo semelhante à fumaça. Pisando ainda mais forte, surgiam, de cada um dos poros, pequenos vermes brancos com pouco mais de $1 \mathrm{~cm}^{6}$, e estes, arrancados com a pinça, deixavam, em seu lugar , pequenos orifícios. Recolocando o nariz na mesma água fervente, e escaldando-o como da primeira vez, o nariz encolhia e adquiria um aspecto normal. Passados dois ou três dias, voltava a coçar, começava a ficar protuberante, intumescia e voltava a crescer. Esse processo era sempre repetido, mas eram mais freqüentes os dias em que o nariz permanecia intumescido.

(3) Desse modo, quando ia comer ou tomar a sua papa de arroz, fazia com que um de seus acólitos enfiasse, por sob o nariz, um bastão de madeira, com cerca de $30 \mathrm{~cm}^{7}$ de comprimento e $3 \mathrm{~cm}$ de largura, e sentado à sua frente, mantivesse-o levantado, até que ele terminasse de comer. Terminada a refeição, o assistente abaixava o nariz e retirava-se.

(4) Quando, por algum motivo, essa tarefa era realizada por outra pessoa, o monge palaciano acabava se aborrecendo com a falta de jeito e recusava-se a comer. Por isso, esse assistente ficou sendo o encarregado de levantar o nariz.

(5) Um certo dia, no entanto, o assistente não pôde comparecer, devido a um mal súbito. Não havendo ninguém que pudesse segurar o nariz, durante a refeição matinal, os outros monges viram-se em apuros, quando um dos serviçais-mirins ${ }^{8}$ comentou: "Eu seria capaz de segurar com

2. Localidade da cidade de Uji, ao sul de Quioto. Uji era um local relativamente movimentado, pois fazia a ligação de Quioto com a cidade de Nara.

3. Refere-se ao termo naiku ou naigubu, referente aos monges que tinham a permissão de freqüentar o recinto religioso denominado Naidôjô, localizado no interior do palácio imperial.

4. Identidade desconhecida

5. Em japonês, 5 ou 6 sun, antiga medida japonesa, onde 1 sun mede cerca de $3 \mathrm{~cm}$.

6. Em japonês, $4 b u$, antiga medida, onde $1 b u=0,3 \mathrm{~mm}$.

7. Em japonês 1 shaku, antiga mediada com cerca de $30,3 \mathrm{~cm}$.

8. Nos templos era freqüente a presença de crianças e adolescentes denominados chigo, que, como aprendizes, realizavam também os serviços gerais do templo. 
jeito. Nada ficaria a dever àquele assistente". Ao ouvir tal comentário, um outro acólito foi contar ao monge palaciano o que ouvira. Esse serviçal-mirim, um adolescente, tinha boa aparência e reunia as condições necessárias para o desempenho da função, em vista do que o monge palaciano concordou, dizendo: "Então, chama esse serviçal-mirim. Já que assim ele diz, vamos fazê-lo segurar isto". O serviçal-mirim foi chamado e conduzido à presença do monge palaciano.

(6) O serviçal-mirim tomou o bastão amparador de nariz, sentou-se comportadamente diante do monge, e fez com que o monge palaciano pudesse tomar a sua papa de arroz, segurando o nariz a uma altura adequada. Enquanto o monge sorvia a papa, comentando: "Esse serviçalmirim é mesmo muito competente. Melhor até que o meu assistente", o serviçal-mirim deu um forte espirro, virando-se para o lado. Nisso, a sua mão tremeu, fazendo movimentar o bastão que sustentava o nariz, razão pela qual o nariz mergulhou na cumbuca de metal, espirrando papa no rosto do monge e do serviçal-mirim.

(7) O monge palaciano ficou furioso, e enquanto retirava a papa do rosto com um papel, expulsava o serviçal-mirim, aos brados: "Tu és um miserável indolente! Tu farias isso, se, em vez do meu, estivesses segurando o venerável nariz de um nobre senhor? 'Seu' idiota, desastrado! Retira-te, moleque!" O serviçal-mirim levantou-se e esgueirou-se a um canto, comentando: "Se houvesse no mundo mais alguém com tamanho nariz, até iria lá para segurá-lo. Que tolice está a dizer o senhor monge!", razão pela qual os acólitos que o ouviram, acorreram para fora e puseramse a rir.

(8) Pensando bem, que tipo de nariz seria realmente? Trata-se de um nariz espantoso!

(9) Todos os que ouviram as incisivas palavras do serviçal-mirim, elogiaram-no. Conta-se que assim foi dito.

A narrativa inicia-se com a apresentação da personagem, Zenchi, caracterizado como uma eminente figura religiosa. A eminência encontra-se sugerida, inicialmente, pelo fato de Zenchi ser um monge palaciano (naiku), fazendo parte, portanto, de um número seleto de monges com permissão de freqüentar o palácio imperial. Além disso, é descrito como um dedicado e respeitado religioso, assim como um competente administrador.

A perfeita conservação das construções, as freqüentes atividades religiosas, a abundância de doações e de oferendas, e até mesmo os detalhes do cotidiano como o banho (levando-se em conta que o banho diário não era habitual, mesmo entre os nobres) traduzem a prosperidade do templo. Assim, o segmento (1) apresenta a concepção tradicional de uma figura religiosa caracterizada pela sua eminência.

No segmento subseqüente (2), entretanto, há uma quebra na seqüência discursiva, marcada por uma expressão interruptiva , "A propósito" (em japonês, sate). Trata-se de uma quebra, na medida em que a imagem social de um eminente monge é substituída pela contrastante imagem pessoal de um monge que, fisicamente, vem retratado através do seu peculiar nariz: um longo nariz que pendia abaixo do seu queixo, e que apresentava um aspecto visual incomum.

Trata-se de um nariz que afigura-se extremamente grotesco, mesmo que não venha a possuir'vida própria , e nem a circular por aí, como conselheiro de Estado, tal qual o do major Kovalióv de $O$ Nariz $^{9}$ que sai desesperadamente à sua procura (a luta de

9. O Nariz, conto do escritor russo Nicolai Gógol (1809 1852), publicado em 1836. 
Zenchi, pelo contrário, resume-se na tentativa de fazer com que o nariz desapareça, ou seja, reduza de tamanho).

O motivo do nariz grande e rubicundo como indicativo de fealdade é encontrado em outras narrativas de Konjaku Monogatarishû como em XXVI / 17 - Sobre o fato de o general Toshihito, quando jovem, conduzir Goi, da Capital para Tsuruga ou XXVIII I 21 - Sobre o apelido de [ ], Diretor de Repartição Pública da Divisão Esquerda da Capital. Além disso, conforme constatado por Propp ${ }^{10}$, pode tornar-se "objeto de zombaria", criando uma impressão cômica ou satírica.

Mais adequado seria dizermos que o nariz de Zenchi afigura-se fisicamente grotesco, e a situação cômica surge em seu encalço. Afigura-se grotesco pela dimensão desmesurada ou a "hiperbolização"11 sofrida pelo órgão olfativo que o torna, de certo modo, uma parte "despedaçada ou autônoma"12 do corpo, na medida em que Zenchi não tem domínio sobre ele (diferentemente do nariz de Pinóquio, cuja mudança de tamanho estava condicionada à mentira, o nariz de Zenchi cresce completamente independente da sua vontade), tampouco consegue exercer qualquer controle motor, precisando ser ele amparado por um bastão, na hora da refeição. Além disso, a sua "transformação em figuras de animais ou de coisas"13 - no presente caso, trata-se de um nariz "tal qual uma casca de laranja" - impõe-lhe um caráter grotesco.

O tratamento utilizado para reduzir o tamanho do nariz lembra a versão doméstica de uma cirurgia plástica, e vem descrito minuciosamente, tal qual num manual de medicina:

- fervia, num bule, a água à alta temperatura; passava o nariz por esse orifício (da bandeja);

- enfiava-o no bule e o escaldava; calçava o nariz e fazia com que o pisassem;

pisando ainda mais forte, surgiam, de cada um dos poros, pequenos vermes brancos; estes (vermes), arrancados com a pinça, deixavam, em seu lugar, pequenos orifícios;

- recolocando o nariz na mesma água fervente, e escaldando-o como da primeira vez, o nariz encolhia;

Note-se que as descrições acima levam-nos a sentir o nariz de Zenchi como um objeto independente, um corpo estranho que o obriga a adotar, durante as refeições, um recurso especial para alimentar-se, com a utilização de um bastão amparador de nariz. E embora incômodo, Zenchi aceita o seu nariz e não se mostra desesperado. Busca soluções, mostra a existência de uma saída, fato que cria a comicidade. Trata-se naturalmente de uma solução que, por si só, se afigura singular, pois está fora do padrões convencionais de alimentação (o fato de ter que levantar o nariz para alimentar-se é

10. V. Propp, Comicidade e Riso, trad. de Aurora Fornoni Bernardini e Homero Freitas de Andrade, São Paulo, Ática, 1992, pp. 52-53.

11. A questão da hiperbolização ou exageração como indicativos do grotesco e/ou do cômico é estudada por autores como Eikhenbaum, Propp e Bakhtin.

12. Cf. Bakhtin, Kayser.

13. M. Bakhtin, A Cultura Popular na Idade Média e no Renascimento: O Contexto de Francois Rabelais, trad. de Yara Frateschi Vieira, São Paulo, Hucitec/Ed. Universidade de Brasília, 1987, p. 276. 
uma exceção, não uma regra). $\mathrm{O}$ tom de seriedade imprimido ao ato de levantar o nariz confere-lhe um ar ritualista, o que acaba também criando a comicidade:

O serviçal-mirim tomou o bastão amparador de nariz, sentou-se comportadamente diante do monge, e fez com que o monge palaciano pudesse tomar a sua papa de arroz, segurando o nariz a uma altura adequada.

A desarmonia dessa cena com as subseqüentes, após o elogio dirigido pelo monge, quanto à competência do serviçal-mirim, acaba provocando uma situação cômica, reforçada pelo esbravejar do monge que, cego pela ira, dirige duras e grosseiras palavras ao serviçal-mirim. Além disso, ele próprio traz à tona aquilo que ninguém ousava comentar: o tamanho do seu nariz. A situação torna-se ainda mais insustentável para o monge, quando, querendo censurar veementemente o serviçal-mirim, acaba cometendo um deslize ainda maior, que provoca o incisivo comentário do serviçal-mirim:

[...] o serviçal-mirim deu um forte espirro, virando-se para o lado. Nisso, a sua mão tremeu, fazendo movimentar o bastão que sustentava o nariz, razão pela qual o nariz mergulhou na cumbuca de metal, espirrando papa no rosto do monge e do serviçal-mirim.

O monge palaciano ficou furioso, e enquanto retirava a papa do rosto com papel, expulsava o serviçal-mirim, aos brados: "Tu és um miserável indolente! Tu farias isso, se, em vez do meu, estivesses segurando o venerável nariz de um nobre senhor? 'Seu' idiota, desastrado! Retira-te, moleque!" O serviçal-mirim levantou-se e esgueirou-se a um canto, comentando: "Se houvesse no mundo mais alguém com tamanho nariz, até iria lá para segurá-lo. Que tolice está a dizer o senhor monge!"

Sobre o "alogismo latente" como recurso cômico, diz Propp que "Apenas alguns o notam e o desmascaram com alguma tirada que revela de repente a estultice e suscita o riso" 14 .

No caso da presente narrativa, o riso, que vinha sendo sugerido desde a apresentação do nariz (o nariz incomum, o bastão amparador, o mergulho dentro da papa de arroz), mas permanecia latente, vai se manifestar no momento em que o defeito físico explicita um defeito de natureza espiritual ${ }^{15}$, ou seja, quando a figura do eminente monge revela o seu lado pessoal, o de um homem tolo (oko), incapaz de enxergar um palmo diante do seu nariz, e que se utiliza de um discurso moralizante que resulta num absurdo: "Tu farias isso, se, em vez do meu, estivesses segurando o venerável nariz de um nobre senhor?"

É interessante observar também a ocorrência de uma inversão hierárquica, quando "aquele que ri" são os acólitos (sociedade) e o "objeto de riso" é o monge palaciano, donde se obtém um efeito grotesco-cômico, através do rebaixamento grotesco das coisas "ao avesso" 16 ou do processo de inversão como quando "rimos do acusado que dá lição

14. V. Propp, op. cit., p. 110.

15. Idem, p. 46.

16. M. Bakhtin, op. cit., p. 10. 
de moral ao juiz, da criança que pretende ensinar aos pais, enfim, do que acabamos de classificar como 'mundo às avessas' "17.

Acrescente-se que o rebaixamento grotesco é realizado ainda no início da narrativa, quando existe o nivelamento de Zenchi com o seu próprio nariz, na medida em que se dá o mesmo grau de importância à apresentação de ambos (cf. segmentos (1) e (2)). A imagem do religioso bem sucedido apresentada no segmento (1), vai ofuscar-se, diante de um problema pessoal, enfrentado pelo homem Zenchi: o tamanho desmesurado do seu nariz (2) que acarreta não só um problema estético, mas um problema de ordem prática, estreitamente ligado ao cotidiano, que é o de não poder alimentar-se como qualquer mortal. A tensão contida que permeia toda a narrativa explode sob a forma de palavras muito duras e vulgares: (7) "miserável indolente", "idiota", "desastrado", "moleque", dirigidas ao serviçal-mirim que o fez "mergulhar" na realidade que Zenchi procurava esquecer-se, protegido pela máscara de um eminente monge palaciano.

Como bem observa Komine Kazuaki ${ }^{18}$, quando os acólitos acorrem para fora e pôem-se a rir, Zenchi se vê isolado, ou seja, há um distanciamento que acarreta uma quebra na harmonia do mundo que, até então, girava em torno dele.

Nesse momento, cai a máscara do eminente monge palaciano (figura religiosa) e surge, em seu lugar, a cômica figura do tolo (oko), com o seu grotesco nariz.

As palavras finais:

Todos os que ouviram as incisivas palavras do serviçal-mirim, elogiaram-no.

convertem-se também numa decisiva dessacralização da figura religiosa, na medida em que o isolamento de Zenchi expande-se do nível religioso (acólitos e serviçal-mirim) para o social ("Todos os que ouviram").

\section{Bibliografia}

AKIYAMA, Ken. “Genji Monogatarito Konjaku Monogatarishû" ("Genji Monogatari e Konjaku Monogatarishû”). Bungaku 6, Coleção Iwanami Kôza. Tóquio, Iwanami Shoten, 1976.

BAKHTIN, Mikhail. A Cultura Popular na Idade Média e no Renascimento - O Contexto de François Rabelais. Trad. Yara Frateschi Vieira. São Paulo, Hucitec/Ed. Universidade de Brasília, 1987.

BERgSON, Henri. O Riso. Trad. Nathanael C. Caixeiro. Rio de Janeiro, Zahar, 1983.

IKEGAMI, Jun'ichi. Konjaku Monogatarishûno Sekai (O Mundo de Konjaku Monogatarishû). Tóquio, Chikuma Shobô, 1983.

MORI, Masato. Konjaku Monogatarishûno Seisei (A Formação de Konjaku Monogatarishû). Osaka, Izumi Shoin, 1986.

NAGANO, Jôichi. Konjaku Monogatarishûno Kanshôto Hihyô (Apreciação e Crítica de Konjaku Monogatarishû). Tóquio, Miei Shoin, 1978.

17. H. Bergson, $O$ Riso, trad. de Nathanael C. Caixeiro, Rio de Janeiro, Zahar, 1983, p. 53.

18. K. Komine, "Setsuwa Bungakuni okeru Seihyôgen" Kokubungaku Kaishakuto Kanshô, vol. 4, Tóquio, Shibunô, 1981, pp. 34-35. 
NANBA, Kizô. "Hana Nagaki Sôno Koto" ("Sobre o Monge do Nariz Longo"). Kokubungaku, vol. 1. Tóquio, Gakutôsha, nov. 1958, pp. 89-92.

OSABE, Hideo. Setsuwano Nakano Yûmoa (O Humor nas Narrativas Setsuwa), Coleção Kanshô Nihon Koten Bungaku 14. Tóquio, Kadokawa Shoten, 1984, pp. 453-460.

Ô, Shukuhô. "Konjaku Monogatarishûni okeru Warai” (“O Riso em Konjaku Monogatarishû"). Nihongo Nihon Bungaku, n. 10. Taipei, Hojin Daigaku Gaigo Gakuin Tôhôgo Bungakukei, dez. 1983, pp. 39-54.

PROPP, Vladimir. Comicidade e Riso. Trad. Aurora Fornoni Bernardini e Homero Freitas de Andrade. São Paulo, Ática, 1992.

SHINOHARA, Shôji. "Han Ôchô Bungakutoshite" ("A Postura de uma Literatura Antiaristocrática"). Kokubungaku, vol. 29. Tóquio, Gakutôsha, 1984, pp. 66-70.

“Oko" (“Tolo”). Kokubungaku, vol. 17. Tóquio, Gakutôsha, 1972, pp. 89-94. 